\title{
ANALISIS GAMBAR FLORA KARYA SISWA KELAS VII SMP NEGERI 36 TAHUN AJARAN 2017/2018 BERDASARKAN UNSUR-UNSUR VISUAL
}

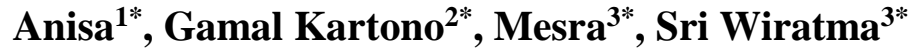 \\ Program Studi Pendidikan Seni Rupa Jurusan Seni Rupa Fakultas Bahasa dan Seni \\ Universitas Negeri Medan \\ Jl. Willem Iskandar Pasar V Medan Estate, Kec, Percut Sei Tuan, Kab. Deli Serdang, Kode Pos 20371 \\ Sumatera Utara. Indonesia \\ Email: annisanisa587@yahoo.com.
}

\begin{abstract}
Abstrak
Penelitian ini bertujuan untuk mengetahui kemampuan siswa dalam menerapkan unsur garis, bentuk, gelap terang, tekstur, ruang/volume serta proporsi pada gambar bunga Mawar karya siswa SMP Negeri 36 Medan Tahun Ajaran 2017/2018. Penelitian ini termasuk pada jenis penelitian kualitatif. Populasi yang terdapat dalam penelitian ini sebanyak 300 karya gambar bunga Mawar, sehingga sampel yang ditetapkan dalam penelitian ini terdiri dari 27 karya gambar bunga Mawar menggunakan teknik Cluster Random Sampling atau pengambilan sampel secara acak/rambang/random. Penilaian dalam penelitian ini mengacu kepada nilai KKM 65 pada mata pelajaran Seni Budaya. Maka Penilaian dalam penelitian menunjukkan bahwa penerapan unsur garis mencapai nilai 71 , unsur bentuk mencapai nilai 64, unsur gelap terang mencapai nilai 61, unsur tekstur mencapai nilai 69 dan ruang/volume mencapai nilai 68, serta penerapan proporsi mencapai nilai 64. Maka dari 6 indikator penilaian tersebut, unsur yang paling unggul dari 6 indikator yaitu pada unsur garis dengan goresan garis yang terlihat spontan, kesan tebal dan tipis juga terlihat pada hasil gambar bunga mawar. Sedangkan penilaian unsur yang paling rendah berada pada unsur gelap terang, dengan penerapan gelap terang yang kurang tepat, baik dari segi tata letaknya maupun dari tekhnik yang diterapkan pada gambar bunga mawar, sehingga kurang menghasilkan dimensi pada gambar objek. Penilaian secara keseluruhan pada unsur garis, bentuk, gelap terang, tekstur, dan ruang/volume mencapai nilai rata-rata 67 dan termasuk dalam kategori cukup baik, serta pada penerapan proporsi mencapai nilai rata-rata 64 dan termasuk dalam kategori kurang baik. Maka dari 27 karya gambar bunga Mawar yang mencapai nilai KKM sebanyak 12 karya atau 44,4 \% dari 27 karya gambar bunga Mawar.
\end{abstract}

Kata Kunci: analisis, gambar, unsur visual

\begin{abstract}
The purpose of the research is to know the ability of the students in apply the line element, shape, dark bright, room/volume and proportion of te picture of the rose by the opus of students SMP Negeri 36 Medan, 2017/2018. This research is a qualitative research. The population of this research is the 300 artwork of a rose, therefore the sample of the research is 27 rose artwork in total which is choosen by using the Cluster Random Sampling technique.assesment in this research refer to score of minimum cumulative criteria 65 in arts lesson. So the assessment in this research show that the application of line element echive until around 71 score, form getting value 64, dark bright getting value 61, texture getting value 69, volume getting value 68, and application of proportion getting value 64. So from the 6 assessment indicators, the most dominant aspect is the line aspect, with a stroke of a line that seems spontaneous, the thick and thin impression is also visible on the rose image. While the assessment of the lowest elements in the dark light, with the application of dark bright that is less precise, bot in terms of layout and the techniques apllied to the image of roses, which causes less dimension on the drawing of the object. The overall assessment of the elements of line, shape, dark light, texture, and space/volume reaches an averages score of 67 and is categorized as good, and the applications of proportions can amoun to an average score of 64, and categorized as not good. Therefore from the total of 27 rose images, the ones that achieve KKM are 12 images in total (44,4\%) out of 27 images of roses.
\end{abstract}

Keywords: analysis, image, visual element. 


\author{
Gorga Jurnal Seni Rupa \\ Volume 07 Nomor 02 \\ p-ISSN: 2301-5942 | e-ISSN: 2580-2380
}

Menjadi batasan masalah diatas adalah :

1.Siswa belum mengetahui cara yang baik dalam menarik garis, membuat bentuk bunga Mawar, menerapkan gelap terang, tekstur, dan ruang/volume pada gambar bunga Mawar dan 2. Penerapan proporsi pada karya gambar bunga Mawar di kelas VII-5 SMP Negeri 36 Medan.

Adapun rumusan masalah pada penelitian ini yaitu :

1. Bagaimanakah penerapan garis, bentuk, gelap terang, tekstur, dan ruang/volume pada gambar bunga Mawar di kelas VII -5 SMP Negeri 36 Medan ? dan 2. Bagaimanakah Penerapan proporsi pada karya gambar bunga Mawar di kelas VII-5 SMP Negeri 36 Medan?.

Adapun tujuan yang diharapkan dari penelitian ini adalah sebagai berikut :

1. Untuk mengetahui kemampuan siswa dalam menerapkan garis, bentuk, gelap terang, tekstur, dan ruang/volume pada gambar bunga Mawar di kelas VII -5 SMP Negeri 36 Medan dan 2. Untuk mengetahui kemampuan siswa dalam menerapkan proporsi pada karya gambar bunga Mawar di kelas VII-5 SMP Negeri 36 Medan.

Manfaat Penelitian dari penelitian ini:

1. Sebagai bahan evaluasi bagi guru seni rupa di SMP Negeri 36 Medan, agar kedepannya hasil karya dari pembelajaran menggambar flora dapat menjadi lebih baik lagi. 2. Sebagai pengetahuan bagi guru di sekolah SMP yang lain, yang juga mengalami persoalan yang sama dalam menggambar bunga Mawar, baik secara faktual, konseptual, dan prosedural. 3. Bagi siswa, dapat menambah pengetahuan dalam memahami unsur-unsur visual dalam menggambar bunga Mawar, baik secara faktual, konseptual, dan prosedural. 4. Bagi sekolah, sebagai bahan literatur disekolah. 5 . Sebagai salah satu referensi bagi peneliti lain yang berkaitan dengan menggambar bunga Mawar dengan menggunakan unsur - unsur visual. 6. Sebagai tambahan literatur bagi Jurusan Seni Rupa Fakultas Bahasa dan Seni Universitas Negeri Medan, dan 7. Bagi peneliti sebagai pegangan dalam melaksanakan tugas kelak sebagai pendidik.

\section{KAJIAN TEORI}

\section{Analisis}

Analisis adalah proses mencari, menguraikan dan menyusun data yang diperolehdari asil wawancara, catatan lapangan, dan dokumentasi sehingga didapat kesimpulan yang akan memudakan orang lain untuk memahaminya. menguasai materi dalam menggambar flora. 


\author{
Gorga Jurnal Seni Rupa \\ Volume 07 Nomor 02 \\ p-ISSN: 2301-5942 | e-ISSN: 2580-2380
}

7.Gelap Terang, merupakan pemberian caaya pada objek dengan menerangi pada bagian-bagian tertentu sehingga terliat perbedaan sisi gelap dan terang yang digunakan untuk memberikan tiga dimensional pada objek. 8.Warna, merupakan unsur rupa yang secara langsung dapat menyentu perasaan, dan 9.Proporsi, merupakan perbandingan dari bagian yang satu dengan bagian yang lainnya dari suatu objek.

\section{Alat-alat Menggambar}

1.Kuas, adalah alat yang digunakan untuk "memasang" cat pada permukaan landasan/kanvas. 2 . Palet, adalah salah satu alat untuk menaruh warna yang dipakai melukis (kadang-kadang berbentuk seperti perisai) dan 3. Pena, adalah alat untuk menulis dengan tinta dibuat dari baja dan segalanya yang runcing dan berbelah.

\section{Bahan-bahan dalam Menggambar}

1.Pensil, adalah batang grafit yang terbungkus kayu lunak seperti cedar, sekitar enam atau tujuh inci panjang dan terbuka di salah satu ujungnya, diantanya Hard Pencil (Pensil Keras) HB, H, 2H, 3H, 4H, 5H, $6 \mathrm{H}, 7 \mathrm{H}$, dan 9H. Soft Pencil (Pensil Lembut) HB, B, 2B, 3B, 4B, 5B, 6B, 7B, 8B, dan 9B. 2.Konte, bentuknya seperti pensil tapi lebi lunak dan tanpa kayu pembungkus. 3.Pastel. 4.Cat Air. 5.Rotring. 6.Kertas Gambar, dan 7.Penghapus.

\section{Menggambar Flora}

Menggambar flora adalah perwujudan suatu gagasan berdasarkan objek flora diatas bidang dengan media dan prinsip tertentu.

\section{Unsur-unsur Visual}

1.Titik, merupakan elemen terkecil yang digunakan dalam menggambar. 2.Garis, merupakan perpaduan sejumlah titik-titik yang dihubungkan sejajar dan sama besar yang memiliki dimensi memanjang serta memiliki arah, bisa pendek, panjang, alus, tebal, berombak, melengkung, lurus dan sebagainya, namun relativ tidak memiliki lebar. 3.Bidang, merupakan unsur visual yang berdimensi panjang dan lebar yang dibatasi oleh garis, baik oleh garis formal maupun garis yang sifatnya ilusif, ekspresif atau sugestif. 4.Bentuk, merupakan elemen yang diperoleh dengan menghubungkan beberapa garis dan dikaitkan dengan wujud. 5.Ruang/Volume, merupakan unsur visual yang menunjukkan kesan keluasan, kedalaman, cekungan, jauh dan dekat. 6.Tekstur, merupakan nilai raba, keadaan suatu permukaan benda dan bentuk kualitas dari suatu permukaan berdasarkan hasil pengamatan, penglihatan dan sentuan teradap permukaan, yang mempunyai nilai raba kasar, lembut, alus, menyengat, nyeri dan sebagainya yang digolongkan menjadi tekstur nyata dan tekstur semu.
Teknik menggambar merupakan cara-cara yang digunakan untuk menggambar. Diantaranya teknik arsir,teknik dusel, teknik pointilis, teknik akuarel,dan teknik plakat.

\section{METODE PENELITIAN}

Metode yang digunakan adalah kualitatif deskriptif, seperti yang dikatakan Satori (2014:25) menurutnya penelitian kualitatif adalah suatu pendekatan dengan mendeskripsikan kenyataan secara benar, dibentuk oleh kata-kata berdasarkan teknik pengumpulan dan analisis data yang relevan yang diperoleh dari situasi yang alamiah. Satori (2014:25), dengan demikian maka peneliti mendeskripsikan hasil karya gambar bunga Mawar dengan cara mengamati unsur visual.

Lokasi penelitian di Jl. STM No. 12 C Kp Baru, Medan, Sumatera Utara, waktu pelaksanaannya dimulai pada tanggal 24 Mei sampai dengan 24 Juli 2018. Lokasi penelitian Populasi dalam penelitian berjumlah 300 karya gambar bunga Mawar, penentuan sampel dalam penelitian ini menggunakan teknik Cluster Random Sampling. teknik Cluster Random Sampling adalah teknik pengambilan sampel penelitian dengan cara acak/rambang/random bila populasi terdiri dari individu-individu yang berada dalam kelompok-kelompok atau rumpun (Sugito. 2017:49). Sehingga jumlah sampel dalam penelitian ini berjumlah 27 karya gambar bunga Mawar yang berada di kelas VII-5.

\section{Rentang Penilaian Karya Siswa}

Tabel. 1. Rentang Penilaian Karya Siswa

\begin{tabular}{|c|c|c|c|}
\hline No. & Rentang Nilai & Kategori & Keterangan \\
\hline 1 & $85-100$ & Sangat Baik & SB \\
\hline 2 & $75-84$ & Baik & CB \\
\hline 3 & $65-74$ & Cukup Baik & KB \\
\hline 4 & $55-64$ & Kurang Baik & \\
\hline
\end{tabular}

\section{Indikator Penilaian Karya Siswa}

\section{1).Garis}

Deskriptor :

Garis yang digoreskan secara spontan/ekspresif

\section{Teknik Menggambar} penelitian yang mengungkapkan situasi social tertentu hasil karya gambar bunga Mawar dilihat dari unsur- 


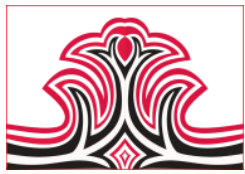

Tidak menampilkan garis kontur pada keseluruhan gambar. Adanya kesan tebal dan tipis pada objek gambar. Garis terlihat jelas.

\section{2).Bentuk}

Deskriptor :

Bentuk objek pada gambar mirip dengan bentuk objek aslinya. Pada bagian bunga Mawar menunjukkan adanya tingkatan kelopak, yang semakin kedalam semakin mengecil. Pada ujung - ujung daunnya terdapat duri - duri kecil. Pada gambar batangnya terdapat duri-duri.

\section{3).Gelap Terang}

Deskriptor :

Letak Gelap terang berdasarkan sumber cahaya. Arsiran yang muncul memberikan kesan gelap terang pada gambar bunga Mawar. Ada perbedaan intensitas cahaya gelap dan terang. Gradasi cahaya jelas.

\section{4).Ruang/ Volume}

Deskriptor :

Adanya cekungan pada gambar kelopak bunga Mawar. Adanya tebal-tipis arsiran pada gambar, sesuai dengan arah cahaya. Adanya kesan lebih gelap pada bagian dalam kelopak bunga Mawar. Tercipta kesan ruang atau kedalaman pada gambar.

\section{5).Tekstur}

Deskriptor :

Tekstur pada gambar objek terlihat sama dengan tekstur pada objek aslinya. Adanya kesan tekstur kasar pada bagian batang dan duri bunga Mawar. Adanya kesan tekstur lembut pada bagian kelopak bunga Mawar. Terdapat teknik dusel pada bagian kelopak untuk memunculkan tekstur lembut.

\section{6).Proporsi}

Deskriptor :

Ukuran bunga lebih besar dari pada batang dan daun bunga Mawar. Ukuran kelopak bunga Mawar pada bagian luar lebih besar di banding dengan kelopak bagian dalam bunga. Ketepatan ukuran perbandingan antara ukuran batang, daun, bunga Mawar. Kesesuaian proporsi antara gambar bunga Mawar dengan kertas gambar.
Gorga Jurnal Seni Rupa

Volume 07 Nomor 02

p-ISSN: 2301-5942 | e-ISSN: 2580-2380

\section{HASIL DAN PEMBAHASAN}

\section{Hasil Penelitian}

Berdasarkan pengumpulan data dan penelitian yang telah dilakukan di SMP Negeri 36 Medan Tahun Ajaran 2017/2018 dilakukan penilaian karya ole penilai I,II, dan III untuk mengetahui hasil penelitian. Hal tersebut akan menghasilkan simpulan menegenai penerapan unsur-unsur visual pada karya gambar bunga Mawar di Kelas VII-5.

Tabel. 2. Rekapitulasi Nilai Gambar Berdasarkan oleh Penilai I, II, dan III

\begin{tabular}{|c|c|c|c|c|c|c|c|c|}
\hline \multirow[t]{2}{*}{ No. } & \multirow[t]{2}{*}{ Penilai } & \multicolumn{6}{|c|}{ Unsur-Unsur Visual } & \multirow{2}{*}{$\begin{array}{l}\text { Nilai } \\
\text { Rata- } \\
\text { Rata }\end{array}$} \\
\hline & & $\mathbf{G}$ & B & GT & $\mathbf{T}$ & $\mathbf{R} / \mathbf{V}$ & $\mathbf{P}$ & \\
\hline 1 & $\mathrm{I}$ & 69 & 64 & 65 & 67 & 67 & 65 & 66 \\
\hline 2 & II & 71 & 64 & 62 & 68 & 65 & 63 & 66 \\
\hline 3 & III & 71 & 67 & 66 & 72 & 71 & 64 & 68 \\
\hline \multicolumn{2}{|c|}{ Jumlah } & 70 & 64 & 61 & 69 & 68 & 64 & 66 \\
\hline
\end{tabular}

Keterangan :

$\mathrm{G} \quad=$ Garis

$\mathrm{B} \quad=$ Bentuk

GT $=$ Gelap Terang

$\mathrm{T}=$ Tekstur

$\mathrm{R} / \mathrm{V}$ = Ruang/Volume

$\mathrm{P} \quad=$ Proporsi

\section{Pembahasan}

Penelitian ini bertujuan untuk mengetahui kemampuan siswa dalam menerapkan unsur garis, bentuk, gelap terang, tekstur, dan ruang/volume pada gambar bunga Mawar di kelas VII-5, serta untuk mengetahui kemampuan siswa dalam penerapan proporsi pada karya gambar bunga Mawar di kelas VII-5 SMP Negeri 36 Medan. Penilaian dalam penelitian ini mengacu kepada nilai KKM 65 pada mata pelajaran Seni Budaya. Maka Penilaian dalam penelitian menunjukkan bahwa penerapan unsur garis mencapai nilai 70 , unsur bentuk mencapai nilai 64 , unsur gelap terang mencapai nilai 61, unsur tekstur mencapai nilai 69 dan ruang/volume mencapai nilai 68 , serta penerapan proporsi mencapai nilai 64. Maka dari 6 indikator penilaian tersebut, unsur yang paling unggul dari 6 indikator yaitu pada unsur garis dengan goresan garis yang terlihat spontan, kesan tebal dan tipis juga terlihat pada hasil gambar bunga mawar. Sedangkan penilaian unsur yang paling rendah berada pada unsur gelap terang, dengan penerapan gelap terang yang kurang tepat, baik dari segi tata letaknya maupun dari tekhnik yang diterapkan pada gambar bunga mawar, sehingga kurang menghasilkan dimensi pada gambar objek.

Penilaian secara keseluruhan pada unsur garis, bentuk, gelap terang, tekstur, dan ruang/volume mencapai nilai rata-rata 67 dan termasuk dalam kategori cukup baik, serta pada penerapan proporsi mencapai nilai rata-rata 64 dan termasuk dalam kategori kurang baik. Maka dari 27 karya gambar bunga Mawar yang 


\section{Gorga Jurnal Seni Rupa \\ Volume 07 Nomor 02 \\ p-ISSN: 2301-5942 | e-ISSN: 2580-2380}

mencapai nilai KKM sebanyak 12 karya atau 44,4 \% dari 27 karya gambar bunga Mawar.

Dari data-data yang telah dideskripsikan, dianalisis serta di interpretasikan pada 27 karya gambar bunga mawar, maka dalam penelitian ini yaitu pada penilaian unsur gelap terang penempatannya belum beraturan, sehingga tidak sesuai dengan arah datangnya cahaya, hal ini tentulah akan berdampak pada hasil gambar, karena fungsi unsur gelap terang adalah untuk memunculkan dimensi pada gambar bunga mawar, kemudian pada pembuatan kelopak mawar juga mengalami kesulitan, siswa belum sepenuhnya bisa membuat kelopak pada gambar bunga mawar yang mereka buat, sehingga dimensi pada gambar bunga mawar belum terlihat dengan jelas.

Dalam penelitian ini juga terdapat beberapa temuan masalah yang berada diluar ruang lingkup penelitian yaitu pada proses pembuatan karya gambar bunga mawar, pada proses ini guru tidak menampilkan objek bunga mawar yang sebenarnya, akan tetapi menampilkan gambar bunga mawar yang terdapat pada buku pelajaran Seni Budaya saja. Sehingga siswa belum bisa memahami dan mengenal objek gambar tersebut dengan baik, hal tersebut tentunya akan berpengaruh besar terhadap hasil karya gambar yang mereka buat. sebagian besar siswa masih banyak yang mengalami kesulitan dalam menggambar karikatur, sehingga nilai rata-rata yang dihasilkan sangat bervariasi.

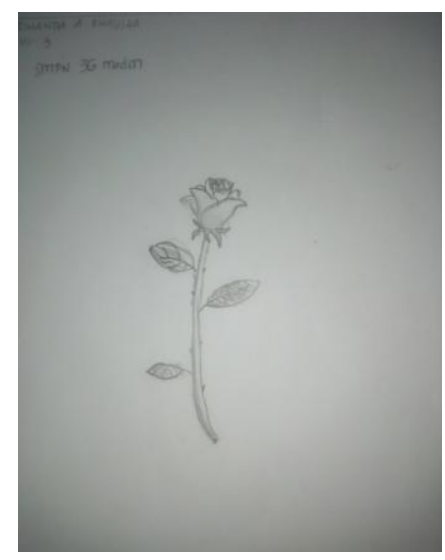

Gambar. 1. Karya Rinanda A Khalila (Sumber: Dokumentasi Foto oleh Anisa, 2018)

Berdasarkan penilaian indikator garis, peneliti melihat kesan garis yang spontan, dan bagus penarikan garisnya, dan dari indikator penilaian bentuk juga lumayan baik dari karya yang lainnya, dalam karya tersebut sudah terlihat perbandingan ukuran bentuk yang sesuai antara bentuk batang, daun dan bunga Mawar. Kemudian jika dilihat dari gelap terangnya terlihat bagus penempatannya, meskipun kurang berani dalam menorehkan arsiran dusel pada kelopak bunga Mawarnya, serta tekstur lembut yang dihasilkan dari sentuhan arsiran dusel juga sudah terlihat pada karya.

Kemudian pada indikator penilaian volume dan proporsi juga terlihat bagus. pada karya Rinanda ini, volume berhasil ia munculkan disetiap lekukan kelopak bunga Mawar tersebut dan proporsi antara batang, daun dan bunga sudah terlihat baik.

\section{1).Analisis Data Kaya}

Tabel. 3. Analisis Data Karya

\begin{tabular}{|l|l|l|}
\hline No. & \multicolumn{2}{|c|}{ INDIKATOR PENILAIAN } \\
\hline 1 & Garis & $\begin{array}{l}\text { Kesan garis yang spontan dan bagus } \\
\text { penarikan garisnya }\end{array}$ \\
\hline 2 & Bentuk & $\begin{array}{l}\text { Dari unsur bentuk sudah lumayan baik, } \\
\text { perbandingan ukuran bentuk juga sudah } \\
\text { sesuai antara batang, daun dan bunga. }\end{array}$ \\
\hline 3 & Gelap Terang & $\begin{array}{l}\text { Penempatan gelap terangnya sudah } \\
\text { teppat dan terlihat bagus. }\end{array}$ \\
\hline 4 & Tekstur & $\begin{array}{l}\text { Tekstur semu dari bunga Mawar sudah } \\
\text { terlihat lembut, karena menerapkan } \\
\text { arsiran dusel. }\end{array}$ \\
\hline 5 & Ruang/Volume & $\begin{array}{l}\text { Volume sudah bagus, terlihat tingkatan- } \\
\text { tingkatan kelopaknya. }\end{array}$ \\
\hline 6 & Proporsi & $\begin{array}{l}\text { Proporsi antara bunga, daun dan batang } \\
\text { sudah terlihat baik perbandingannya }\end{array}$ \\
\hline
\end{tabular}

Tabel. 4. Rekapitulasi Nilai Gambar Berdasarkan oleh Penilai I, II, dan III

\begin{tabular}{|l|c|c|c|c|}
\hline \multirow{2}{*}{$\begin{array}{c}\text { Indikator yang } \\
\text { dinilai }\end{array}$} & $\begin{array}{c}\text { Penilai } \\
\text { I }\end{array}$ & $\begin{array}{c}\text { Penilai } \\
\text { II }\end{array}$ & $\begin{array}{c}\text { Penilai } \\
\text { III }\end{array}$ & $\begin{array}{c}\text { Nilai } \\
\text { Rata-rata }\end{array}$ \\
\cline { 2 - 4 } & Nilai & Nilai & Nilai & \\
\hline Garis & 85 & 97 & 85 & 89 \\
\hline Bentuk & 80 & 85 & 85 & 83 \\
\hline Gelap terang & 80 & 90 & 85 & 85 \\
\hline Tekstur & 80 & 96 & 85 & 87 \\
\hline Ruang/Volume & 80 & 88 & 85 & 84 \\
\hline Proporsi & 85 & 85 & 80 & 83 \\
\hline Jumlah & $\mathbf{4 9 0}$ & $\mathbf{5 4 1}$ & $\mathbf{5 0 5}$ & $\mathbf{5 1 1}$ \\
\hline Nilai Rata-rata & $\mathbf{8 1}$ & $\mathbf{9 0}$ & $\mathbf{8 4}$ & $\mathbf{8 5}$ \\
\hline
\end{tabular}

\section{2). Interpretasi Hasil Pengolahan Data (Penafsiran Data)}

Berdasaran analisis data yang telah dipaparkan di atas, maka dapat ditarik kesimpulan interpretasi data atau penafsiran data yang diperoleh pada karya 22 mendapat kategori Sangat Baik pada indikator garis, gelap terang, dan juga tekstur. Kemudian kategori Baik berada pada indikator bentuk, ruang/volume dan proporsi. Dengan demikian keunggulan pada karya 22 ini terletak pada garisnya yang spontan, sehingga keluwesan bentuk batang, kelopak maupun daun dapat terlihat dengan jelas, kemudian pada bagian tekstur juga terlihat bagus, tekstur lembut terdapat pada bagian kelopak yang hadir karena sentuhan teknik dusel. 


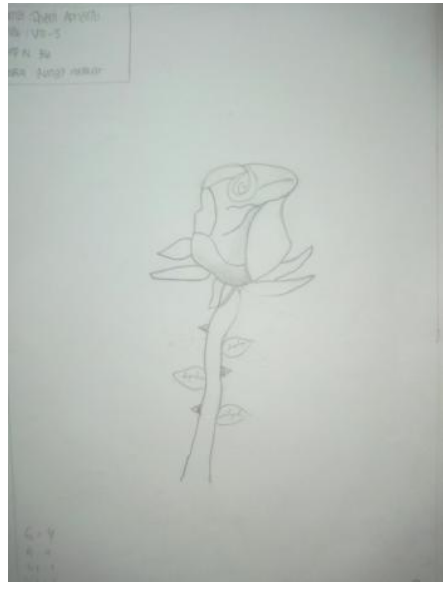

Gambar. 2. Karya Sheni Aprianti (Sumber: Dokumentasi Foto oleh Anisa, 2018)

Berdasarkan pengamatan peneliti atas karya Sheni, keluwesan garis sudah terlihat, hanya saja terlalu banyak tekanan yang terdapat pada gambar tersebut, sehingga tidak ada kesan tebal tipisnya garis pada keseluruhan gambar. Kemudian mengenai unsur bentuk juga harus diperhatikan kembali pada keseluruhan bentuk nya, bentuk batang masih terlalu besar dan tidak menunjukkan karakter dari batang bunga Mawar. Pada indikator gelap terang juga sama sekali tidak tampak, sehingga tidak ada tekstur dan volume yang terlihat pada gambar tersebut. Dan yang terakhir mengenai proporsi yang masih belum jelas, jika sekilas dilihat maka tidak akan tampak bahwa itu adala gambar bunga Mawar, sebab proporsi batang yang terlihat gemuk tidak sesuai dengan batang maear, begitu juga dengan proporsi daun yang terlalu kecil dibandingkan dengan ukurang batang dan bunga Mawarnya.

\section{3).Analisis Data Karya}

Tabel. 5. Analisis Data Karya

\begin{tabular}{|l|l|l|}
\hline No. & \multicolumn{2}{|c|}{ INDIKATOR PENILAIAN } \\
\hline 1 & Garis & $\begin{array}{l}\text { Keluwesan garis sudah terlihat, hanya } \\
\text { saja terlalu ditekan ketika menarik } \\
\text { garisnya, sehingga secara keseluruhan } \\
\text { garisnya terlihat seperti garis outline. }\end{array}$ \\
\hline 2 & Bentuk & $\begin{array}{l}\text { Bentuk batang terlalu besar untuk } \\
\text { ukuran bunga seperti itu, dan terlihat } \\
\text { ketidakteraturan besar atau kecilnya } \\
\text { ukuran batang. } \\
\text { Bentuk kelopak belum memperlihatkan } \\
\text { lipatan-lipatan kelopakknya secara } \\
\text { baik. }\end{array}$ \\
\hline 3 & Gelap Terang & $\begin{array}{l}\text { Gelap terang sama sekali belum } \\
\text { diterapkan. }\end{array}$ \\
\hline 4 & Tekstur & $\begin{array}{l}\text { Tekstur lembut belum terlihat pada } \\
\text { gambar kelopak }\end{array}$ \\
\hline 5 & Ruang/Volume & Volume pada gambar sudah terlihat, \\
\hline
\end{tabular}

namun belum maksimal khususnya pada bagian kelopak.

Proporsi secara keseluruhan belum tepat ukurannya, termasuk pada proporsi batang yang masih besar kecil.

Tabel. 6. Rekapitulasi Nilai Gambar Berdasarkan oleh Penilai I, II, dan III

\begin{tabular}{|l|c|c|c|c|}
\hline \multirow{2}{*}{$\begin{array}{c}\text { Indikator yang } \\
\text { dinilai }\end{array}$} & $\begin{array}{c}\text { Penilai } \\
\text { I }\end{array}$ & $\begin{array}{c}\text { Penilai } \\
\text { II }\end{array}$ & $\begin{array}{c}\text { Penilai } \\
\text { III }\end{array}$ & $\begin{array}{c}\text { Nilai } \\
\text { Rata-rata }\end{array}$ \\
\cline { 2 - 4 } & Nilai & Nilai & Nilai & \\
\hline Garis & 78 & 90 & 78 & 82 \\
\hline Bentuk & 70 & 70 & 80 & 73 \\
\hline Gelap terang & 60 & 60 & 60 & 60 \\
\hline Tekstur & 70 & 80 & 70 & 73 \\
\hline Ruang/Volume & 80 & 80 & 80 & 80 \\
\hline Proporsi & 75 & 70 & 70 & 71 \\
\hline Jumlah & $\mathbf{4 3 3}$ & $\mathbf{4 5 0}$ & $\mathbf{4 3 8}$ & $\mathbf{4 3 9}$ \\
\hline Nilai Rata-rata & $\mathbf{7 2}$ & $\mathbf{7 5}$ & $\mathbf{7 3}$ & $\mathbf{7 3}$ \\
\hline
\end{tabular}

\section{4). Interpretasi Hasil Pengolahan Data (Penafsiran Data)}

Berdasaran analisis data yang telah dipaparkan di atas, maka dapat ditarik kesimpulan interpretasi data atau penafsiran data yang diperoleh pada karya 23 mendapat kategori Baik pada indikator garis dan juga ruang/volume. Kemudian kategori Cukup baik berada pada indikator bentuk, dan juga proporsi Sedangkan kategori Kurang Baik berada pada indikator gelap terang dengan nilai 60. Dengan demikian keunggulan pada karya 23 terletak pada garisnya yang spontan dan kekurangannya terletak pada gelap terang yang penempatannya kurang tepat, sehingga dimensi yang dihadirkan kurang terlihat pada gambar.

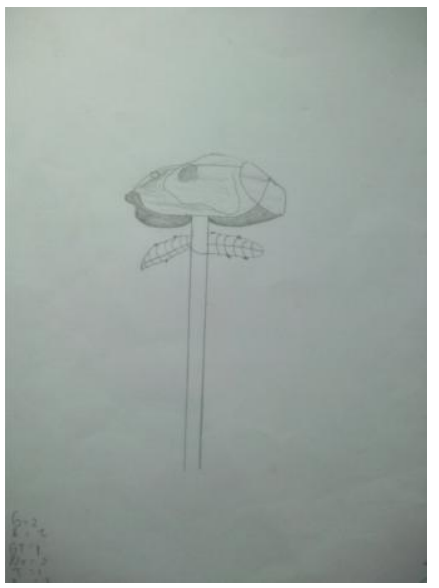

Gambar. 3. Karya Diva Febiola

(Sumber: Dokumentasi Foto oleh Anisa, 2018)

Berdasarkan penilaian indikator garis, karya tersebut mempunyai kesan garis belum spontan, garis pada batang juga masih sama dengan karya-karya yang lainnya yaitu terkesan kaku, disebabkan oleh tarikan garis yang menggunakan penggaris. Dari segi bentuk secara keseluruhan belum maksimal, detail-detail pada objek masih tidak terlihat jelas sehingga bila dilihat 


\section{Gorga Jurnal Seni Rupa \\ Volume 07 Nomor 02 \\ p-ISSN: 2301-5942 | e-ISSN: 2580-2380}

sekilas orang lain, tidak dapat disimpulkan benda apa yang digambarkan diatas. Tidak hanya itu, peneliti juga mengamati indikator gelap terang yang belum sesuai dengan arah datangnya cahaya. Kemudian pada indikator tekstur juga sama dengan karya yang lain, yaitu masih terkesan kaku pada bagian batang bunga Mawarnya, dan yang terakhir mengenai indikator volume dan proporsi, secara keseluruhan kelopak bunga Mawar pada karya tersebut belum menunjukkan adanya volume, karna volume akan muncul ketika kelopak demi kelopak itu disatukan sehingga akan membentuk lekukan - lekukan pada bunga Mawar, dan mengenai proporsi sebaiknya perlu diperhatikan kembali agar bentuk bunga Mawar dapat digambarkan dengan baik.

\section{5).Analisis Data Karya}

Tabel. 7. Analisis Data Karya

\begin{tabular}{|c|c|c|}
\hline No. & \multicolumn{2}{|c|}{ INDIKATOR PENILAIAN } \\
\hline 1 & Garis & $\begin{array}{c}\text { Garis masih terlihat kaku disebabkan } \\
\text { oleh tarikan garis yang menggunakan } \\
\text { penggaris. }\end{array}$ \\
\hline 2 & Bentuk & $\begin{array}{c}\text { Bentuk gambar bunga Mawar belum } \\
\text { maksimal, detail-detail objek masih } \\
\text { belum terlihat jelas. }\end{array}$ \\
\hline 3 & Gelap Terang & $\begin{array}{c}\text { Gelap terang belum sesuai dengan arah } \\
\text { datangnya cahaya. }\end{array}$ \\
\hline 4 & Tekstur & Tekstur terlihat polos. \\
\hline 5 & Ruang/Volume & $\begin{array}{c}\text { Volume tidak tampak pada karna } \\
\text { khususnya pada bagian bunga, karna } \\
\text { pada bagian bunga tidak terdapat } \\
\text { susunan kelopak demi kelopak yang } \\
\text { dapat memunculkan volume pada } \\
\text { karya. }\end{array}$ \\
\hline 6 & Proporsi & $\begin{array}{c}\text { Sekilas jika dlihat proporsinya masih } \\
\text { sangat berantakan. }\end{array}$ \\
\hline
\end{tabular}

Tabel. 8. Rekapitulasi Nilai Gambar Berdasarkan oleh Penilai I, II dan III

\begin{tabular}{|l|c|c|c|c|}
\hline \multirow{2}{*}{$\begin{array}{c}\text { Indikator yang } \\
\text { dinilai }\end{array}$} & $\begin{array}{c}\text { Penilai } \\
\text { I }\end{array}$ & $\begin{array}{c}\text { Penilai } \\
\text { II }\end{array}$ & $\begin{array}{c}\text { Penilai } \\
\text { III }\end{array}$ & \multirow{2}{*}{$\begin{array}{c}\text { Nilai } \\
\text { Rata-rata }\end{array}$} \\
\cline { 2 - 4 } & Nilai & Nilai & Nilai & \\
\hline Garis & 65 & 65 & 70 & 66 \\
\hline Bentuk & 60 & 60 & 60 & 60 \\
\hline Gelap terang & 60 & 62 & 60 & 60 \\
\hline Tekstur & 60 & 60 & 60 & 60 \\
\hline Ruang/Volume & 60 & 60 & 60 & 60 \\
\hline Proporsi & 60 & 55 & 60 & 58 \\
\hline Jumlah & $\mathbf{3 6 5}$ & $\mathbf{3 6 2}$ & $\mathbf{3 7 0}$ & $\mathbf{3 6 4}$ \\
\hline Nilai Rata-rata & $\mathbf{6 0}$ & $\mathbf{6 0}$ & $\mathbf{6 1}$ & $\mathbf{6 0}$ \\
\hline
\end{tabular}

\section{6). Interpretasi Hasil Pengolahan Data (Penafsiran} Data)

Berdasaran analisis data yang telah dipaparkan di atas, maka dapat ditarik kesimpulan interpretasi data atau penafsiran data yang diperoleh pada karya 9 mendapat kategori Cukup Baik pada indikator garis. Kemudian kategori Kurang Baik berada pada indikator bentuk, gelap terang, tekstur, ruang/volume, dan juga proporsi.
Dengan demikian keunggulan pada karya 9 terletak pada unsur garis yang spontan dan tegas pada keseluruhan gambar dan kekurangannya terletak pada bagian proporsi batang yang sangat lurus, proporsi daun yang terlihat memanjang serta ukuran kelopak yang tidak beraturan, sehingga hal itu membuat gambar kurang menyerupai bentuk objek.

\section{KESIMPULAN DAN SARAN}

\section{Kesimpulan}

Kemampuan siswa dalam menerapkan unsur garis, bentuk, gelap terang, tekstur, ruang/volume pada karya gambar bunga Mawar di kelas VII-5 SMP Negeri 36 Medan rata-rata mencapai nilai (67) dan termasuk dalam kategori Cukup Baik dan 2.Kemampuan siswa dalam menerapkan proporsi pada karya gambar bunga Mawar di kelas VII-5 SMP Negeri 36 Medan rata-rata mencapai nilai (64) dan termasuk dalam kategori Kurang Baik.

\section{Saran}

Berdasarkan hasil penilaian, analisis dan simpulan penelitian, maka peneliti menyarankan :

\section{1).Bagi Guru}

1.Berdasarkan kompetensi inti dari struktur kurikulum K13, sebaiknya guru menjelaskan hal-hal faktual yang berkaitan dengan landasan - landasan teoritis yang bersifat pengetahuan sesuai dengan tujuan pembelajaran berdasarkan indikator-indikator yang digunakan. 2.Guru menjelaskan hal-hal konseptual yang berkaitan dengan ciri suatu objek sehingga anak mampu menangkap ciri objek tersebut. 3.Guru menjelaskan prosedural atau langkah-langkah dalam menggambar objek sesuai dengan tujuan pembelajaran. 4.Guru menggunakan objek secara langsung, bukan dari media gambar yang digunakan untuk menggambar. 5.Guru memberi latihan menarik bermacam-macam bentuk garis. 6.Guru mampu menjelaskan kesalahan-kesalahan siswa dalam menggambar.

\section{2).Bagi Siswa}

1.Dalam menggambar siswa harus bisa mengamati objek yang ada di hadapannya sehingga bisa mengetahui konsep/ciri suatu objek, begitu juga perbandingan-perbandingan atau proporsi setiap bagian objek, dengan difasilitasi dan dimotivasi oleh guru. 2.Siswa harus berlatih lebih sering lagi untuk membuat tarikan garis yang lebih luwes, berlatih mengarsir objek gambar dengan baik agar gambar tersebut dapat terlihat gelap terangnya.

\section{3).Bagi Sekolah}




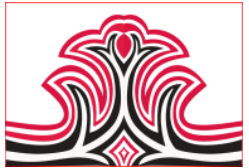

1.Kepada sekolah disarankan untuk lebih banyak membantu siswa-siswi dalam pengadaan referensi sebagai bahan pengetahuan yang lebih untuk memperkaya pengetahuan siswa khususnya dalam materi menggambar. 2.Pihak sekolah hendaknya memfasilitasi kegiatan ekstra kurikuler menggambar bagi siswa, agar kedepannya siswa-siswi dapat berlatih dengan lebih baik dalam bidang menggambar, sehingga kedepannya siswa-siswi SMP Negeri 36 dapat menghasilkan karya-karya yang berkualitas baik, dengan menerapkan unsur-unsur visual seni rupa dalam karya gambar yang mereka buat.

\section{4).Bagi Jurusan}

1.Bagi jurusan Seni Rupa disarankan untuk memberikan penguatan terhadap mahasiswa/i dalam pengetahuan mereka mengenai unsur-unsur visual Seni Rupa, agar kedepannya saat mahasiswa/i Jurusan Seni Rupa menjadi guru, mereka bisa menjadi guru yang profesional, baik dalam segi pengetahuan maupun prakteknya.

\section{5).Bagi Peneliti}

1.Sebagai pedoman ilmu pengetahuan yang akan digunakan ketika menjadi seorang guru saat mengajar di sekolah.

2.Sebagai motivasi bagi peneliti agar menjadi seorang guru yang dibekali dengan ilmu pengetahuan dan juga dalam praktek.

\section{DAFTAR RUJUKAN}

Satori, Djam'an dan Aan Komariah. 2014. Metodologi Penulis Kulitatif. Bandung : Alfabeta.

Sugito, dkk. 2017. Metode Penelitian pendidikan Seni Rupa. Medan: Unimed Press. 